\title{
Foreword
}

\section{Symposium on Bulk Metallic Glasses VIII}

Bulk metallic glasses (BMGs) were discovered about 20 years ago, in the 1990s, when Inoue's group and Johnson's group found new BMG compositions with excellent glass-forming ability. Owing to their amorphous structure, BMGs have many unique properties, such as superior strength with high elastic limits, excellent scratch and wear resistance, and good corrosion resistance. Therefore, BMGs have attracted great attention. With the discovery of new processing methods, for example, beating crystallization by millisecond heating and processing, as well as new BMG compositions with promising properties, for instance, damage-tolerant Pd-based BMGs, BMGs remain prosperous as potential structural and functional materials.

In order to strengthen the communication in the community of BMGs, a Bulk Metallic Glasses Symposium has been held successfully at The Minerals, Metals \& Materials Society (TMS) Annual Meeting since 2004. The TMS Structural Materials Division and the TMS/American Society for Metals (ASM): Mechanical Behavior of Materials Committee kindly sponsored our Bulk Metallic Glasses Symposium. The Bulk Metallic Glasses VIII Symposium was successfully held at the 2011 TMS Annual Meeting \& Exhibition, San Diego, CA, February 27-March 3, 2011. A total of 125 presentations, including 2 keynotes and 60 invited talks, were given during the meeting. The topics of the Bulk Metallic Glasses Symposium involved a wide range of BMG research areas, such as alloy development and application, mechanical behavior, microstructure characterization, fatigue and corrosion, and simulation and modeling.

We express our sincere appreciation to all the attendees for contributing to the success of our Bulk Metallic Glasses Symposium. We want to acknowledge the sponsorship from TMS and ASM. All submitted manuscripts were subjected to the standard peer-review procedures of the Metallurgical and Materials Transactions A journal. A total of 21 papers were accepted for publishing in the current issue. We are very grateful to all the key readers, the reviewers, and the staff of Metallurgical and Materials Transactions A, especially Ms. Dora Moscatello, Ms. Mary Lynn Brown, and Professor David E. Laughlin, for their kind help in the preparation and approval of the Symposium publication.

We greatly acknowledge the financial support of the National Science Foundation (NSF) through (1) the International Materials Institutes under Grant No. DMR-0231320, (2) the Combined Research and Curriculum Development Programs under Grant Nos. EEC-9527527 and EEC-0203415, (3) the Division of Civil, Mechanical, Manufacture, and Innovation Program under Grant Nos. CMMI-0900271 and CMMI-1100080, and (4) the Materials World Network Program under Grant No. DMR-0909037 at The University of Tennessee, Knoxville (UTK), with Dr. C. Huber, Ms. M. Poats, Dr. C.V. Cooper, Dr. A. Ardell, and Dr. D. Finotello of NSF as the program directors, respectively. The financial support from the Center for Materials Processing at UTK, with Dr. C.J. McHargue as the director, is sincerely acknowledged.

Symposium Organizers

Peter K. Liaw (pliaw@utk.edu)

Gongyao Wang (gwang@utk.edu)

HahnChoo (hchoo@utk.edu)

Yanfei Gao (ygao7@utk.edu) 